\title{
Kinetic Modeling of Methylene Blue and Crystal Violet Dyes Adsorption on Alginate-Fixed Water Hyacinth in Single and Binary Systems
}

\author{
Courtie Mahamadi", Epias Mawere \\ Chemistry Department, Bindura University of Science Education, Bindura, Zimbabwe \\ Email: courtiema@yahoo.com, cmahamadi@buse.ac.zw
}

Received August 6, 2013; revised September 6, 2013; accepted October 3, 2013

Copyright (C) 2013 Courtie Mahamadi, Epias Mawere. This is an open access article distributed under the Creative Commons Attribution License, which permits unrestricted use, distribution, and reproduction in any medium, provided the original work is properly cited.

\begin{abstract}
Removal of Methylene Blue (MB) and Crystal Violet (CV) dyes from monocomponent and binary aqueous solutions by water hyacinth- $E$. Crassipes roots fixed on alginate (a low-cost adsorbent) has been investigated. The extent of adsorption was evaluated as a function of solution $\mathrm{pH}$, initial dye concentration, and bead biomass loading. Kinetic sorption data were analysed by widely used models: pseudo-first-order, pseudo-second-order, Elovich, and intraparticle diffusion models. The results showed that pseudo-second-order model better described the biosorption experimental data than the pseudo-first-order kinetic model for both dyes, whilst the Elovich model fitted the biosorption experimental data at lower dye concentrations. The intraparticle diffusion model indicated that sorption of CV and MB was characterized by rapid surface adsorption coupled with slow film diffusion process at higher initial dye concentration and at all initial bead biomass loading. The range of mean free energy values confirmed physical adsorption as the mechanism for dye removal from solution.
\end{abstract}

Keywords: Eichhornia crassipes; Adsorption; Kinetic Models; Methylene Blue; Crystal Violet

\section{Introduction}

Increasing global production, possible toxic effects and persistence in the environment has resulted in dye pollution emerging as a significant environmental pollution issue over the past few decades [1]. Various treatment processes have been studied for dye removal from wastewater and these include physical separation, advanced chemical oxidation, and biological degradation [2-7]. However, these methods are expensive to operate and may produce toxic by-products. Activated carbon has been established as an effective adsorbent due to its large surface area, low density and chemical stability, but its high costs of manufacturing and regeneration make its use for large scale wastewater treatment uneconomical. These drawbacks associated with activated carbon have generated the interest for the development of its low-cost alternatives using a range of carbonaceous and other precursors.

Recently, use of organisms including bacteria, fungi, algae and plants as adsorbents has been developed as a

"Corresponding author. low-cost and eco-friendly viable alternative [8,9]. In particular, biosorption, which involves dye removal from aqueous solution by passive linkage in live and dead biomasses in a mechanism that is not controlled by metabolic steps, is proving to be a popular alternative owing to its several advantages. These include simplicity of design, great efficiency for dye removal at low concentration, potential for biosorbent regeneration, high velocity of sorption and desorption, limited generation of secondary residues and more environmentally friendly life cycle of the material (e.g. easy to eliminate compared to conventional resins) $[8,9]$. Low-cost biomasses which have been investigated for their capacity to remove dyes from solution include peel of fruit, potato plant wastes and dried algae and ferns [10-12]. MB and CV are typical basic dyes that have been removed from aqueous solution using various adsorbents such as sawdust [13]; pineapple leaf powder [14]; Calotropis procera [15], coniferous pinus bark powder [16], palm kernel fiber [17], and silkworm exuviae [18].

Generally, for a given biomass being studied for biosorption potential for the first time, the sorption process 
is initially carried out using native biomasses in the ground, fine powdered form in batch systems. Despite of the continuous operation in columns to be the preferential mode for amplifying the biosorption process to a pilot scale, the batch systems serve as pre-stage for an initial evaluation of adsorption phenomena and operational conditions before the application of the process on continuous systems. The batch systems have several advantages such as high rapid steady-state attainment, high biosorption capacity, less process cost and good particle mass transfer. However, they often suffer several drawbacks, and these include low biomass density, solid-liquid separation problems, possible biomass swelling, inability to regenerate/reuse and development of high pressure drop in the column mode [19]. To improve the mechanical properties of biosorbents, immobilization, which uses techniques such as entrapment and crosslinking, has been reported [20,21]. Immobilization of biosorbent material offers advantages including the control of particle size, regeneration and reuse of the biomass, easy separation of biomass and effluent, high biomass loading and minimal clogging under continuous-flow conditions [22-26]. Common immobilization matrices used include sodium alginate, polysulphone, polyacrylamide, and polyurethane [21,27-29].

Many studies have shown that $E$. crassipes can effectively remove heavy metals from aquatic systems because of the functional groups on the cell wall and their high binding affinity, fast growth and high abundance around the world [30-34]. However, of the few reports on the biosorption of dyes from contaminated waters using E. crassipes [29], none have reported on dye removal using immobilized biosorbent. The aim of the present study was to investigate the removal of MB and CV dyes by dried root biomass of E. crassipes immobilized on alginate. To obtain a better understanding of the biosorption mechanisms, the effect of initial dye concentration, $\mathrm{pH}$ and amount of bead biomass loading were studied for batch monocomponent and binary systems. The kinetic data generated were analysed using pseudo-first-order, pseudo-second-order, Elovich, and intraparticle diffusion models.

\section{Experimental}

\subsection{Instrument}

The concentrations of MB and CV dyes in the solutions before and after biosorption were determined by Genesys $10 \mathrm{~S}$ (Thermo Scientific) UV/VIS Spectrophotometer. The $\mathrm{pH}$ of the solution was measured with a Cheker $\mathrm{pH}$ meter (Hanna Instruments, UK). All experiments were repeated twice with a repeatability of the results showing a variation of coefficient lower than $5 \%$.

\subsection{Chemicals and Reagents}

$\mathrm{MB}$ and $\mathrm{CV}$ stock solutions were prepared by dissolving known quantities of analytical reagent grade $\mathrm{MB}$, $\left(\mathrm{C}_{16} \mathrm{H}_{18} \mathrm{ClS} \cdot \mathrm{H}_{2} \mathrm{O}(\mathrm{x}=2.3)\right.$, (C.I. 52015, M.W. 319.86)) supplied by Thomas Baker (Chemicals) Ltd., India and $\mathrm{CV},\left(\mathrm{C}_{25} \mathrm{H}_{30} \mathrm{~N}_{3} \mathrm{Cl}\right.$ (CI 42555, M.W. $\left.\left.407.98 \mathrm{~g} / \mathrm{mol}\right)\right)$ supplied by Saarchem Ltd., SA. The two basic dyes were chosen because they have well separated absorption peaks in binary solution (663 nm for MB and $590 \mathrm{~nm}$ for $\mathrm{CV}$ ). Stock solutions of $1,000 \mathrm{mg} / \mathrm{L}$ of $\mathrm{MB}$ and $\mathrm{CV}$ were prepared using de-ionised water and used to obtain standard solutions.

\subsection{Procedure}

\subsubsection{Preparation of Biosorbent}

Sodium alginate salt purchased from Sigma Aldrich (Germany) was used as hydrocolloidal gelling material. As fixing solution, a $\mathrm{CaCl}_{2}$ (Sigma Aldrich, Germany) solution was utilized. A $2 \%(\mathrm{w} / \mathrm{v})$ sodium alginate solution was prepared by dissolving $2 \mathrm{~g}$ of sodium alginate in $100 \mathrm{~mL}$ of deionised water and then agitated for 24 hours at $300 \mathrm{rpm}$ to make a homogenous polymer solvent mixture. Biomass sampling and propagation has been described previously [39]. Biomass powder, $(2-10 \mathrm{~g})$ was then blended with $100 \mathrm{~mL}$ of $2 \% \cdot \mathrm{w} / \mathrm{v}$ sodium alginate solution to make beads with biomass loadings of $2 \%$ $10 \%$. Spherical beads were prepared by dropping the mixed solution into a $0.1 \mathrm{M}$ calcium chloride solution. Beads 3 - $5 \mathrm{~mm}$ in diameter were formed by drop-wise extrusion through a pipette tip. The beads were hardened by placing them in $2 \%$ calcium chloride solution for 12 hours and washed in deionised water by agitation at 100 rpm for $30 \mathrm{~min}$, discarding the solution, and then repeating the process 5 times. After removing residual water with paper towels, the beads were dried gradually at room temperature to constant weight and then used for further experiments [34].

\subsection{Adsorption of $M B$ and $C V$ onto Alginate-Fixed E. crassipes}

\subsubsection{Optimum Biomass Loading}

The optimum bead biomass loading for dye sorption was determined by contacting $0.1 \mathrm{~g}$ of adsorbent of biomass loadings of $2 \%, 4 \%, 6 \%$ and $8 \%(\mathrm{w} / \mathrm{v})$ separately with 50 $\mathrm{mL}$ solution of each dye at initial concentration of 50 $\mathrm{mg} / \mathrm{L}$. The initial $\mathrm{pH}$ of the dye solution was set at 8 and the mixture was agitated at $150 \mathrm{rpm}$ at room temperature, filtered through $0.45 \mu \mathrm{m}$ Millipore ${ }^{\circledR}$ cellulose filters and dye remaining concentrations were determined in the filtrate.

\subsubsection{Effect of $\mathrm{pH}$}

The effect of $\mathrm{pH}$ on the adsorption of $\mathrm{MB}$ and $\mathrm{CV}$ in 
monocomponent dye solutions was studied with aqueous solutions of $50 \mathrm{mg} / \mathrm{L}$ dye concentration. The initial $\mathrm{pH}$ was varied in the range $\mathrm{pH} 3-10$ using $0.1 \mathrm{M} \mathrm{HNO}_{3}$ and $0.1 \mathrm{M} \mathrm{Na}_{2} \mathrm{CO}_{3}$. Fifty millilitres of dye solutions were mixed with $0.1 \mathrm{~g}$ of $6 \%$ biomass loading, agitated at 150 $\mathrm{rpm}$ for $5 \mathrm{hr}$ at $30^{\circ} \mathrm{C}$. After that, aliquots were filtered through $0.45 \mu \mathrm{m}$ Millipore ${ }^{\circledR}$ cellulose filters and dye remaining concentrations were determined in the filtrate.

\subsubsection{Kinetic Study}

In order to determine the equilibrium time and sorption mechanism, adsorption tests were conducted with solutions containing $50 \mathrm{mg} / \mathrm{L}$ of $\mathrm{MB}$ and $\mathrm{CV}$ dyes in monocomponent and binary systems respectively. A fixed dose of $0.5 \mathrm{~g}$ of $6 \%$ biomass loading was mixed with $50 \mathrm{~mL}$ of each dye solution. The mixtures were agitated at $150 \mathrm{rpm}$, filtered at pre-set times up to a maximum of $200 \mathrm{~min}$, and analyzed for remaining dye concentration.

\subsubsection{Binary Dye Sorption}

For binary dye aqueous solution systems, a 1:1 dye concentration ratio was used, and the equilibrium sorption for each dye in the binary mixture was determined at the individual dye's previously stated maximum absorption wavelength. The sorption parameters and conditions used were as described previously for monocomponent dye systems.

\section{Results and Discussion}

\subsection{Optimum Biomass Loading}

The reasons for studying the effect of adsorbent dosage on sorption dynamics are mainly economical: to establish the effectiveness of an adsorbent and the ability of a solute to be adsorbed with a minimum dosage. Figure 1 shows the removal efficiency (\%) of $\mathrm{MB}$ and $\mathrm{CV}$ dyes

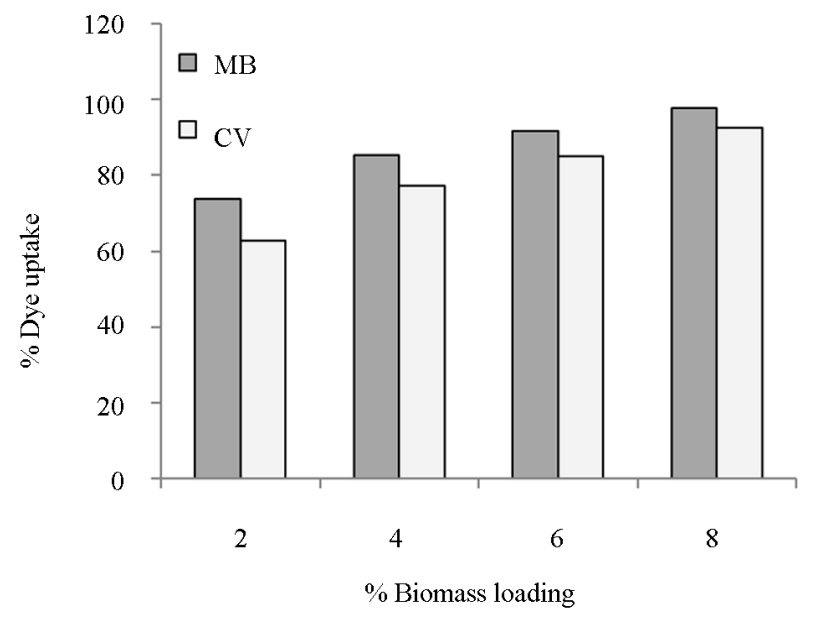

Figure 1. Effect of bead biomass loading on sorption of MB and $\mathrm{CV}$ onto alginate-E. crassipes beads. versus bead biomass loading (\%) for a fixed biomass dose of $2 \mathrm{~g} / \mathrm{L}$ at initial dye concentration of $50 \mathrm{mg} / \mathrm{L}$. As it can be seen in Figure 1, the removal of both dyes is dependent upon the biomass loading in the beads. Dye removal is enhanced with increasing amount of biomass in the beads. Maximum removal efficiencies of 93 and $97 \%$ were achieved with a biomass loading of $8 \%$ for CV and $\mathrm{MB}$ respectively. Use of higher biomass loadings was not possible as the beads formed at biomass loadings greater than $8 \%$ were not stable in aqueous solution. It can also be seen that at all bead biomass loadings, the biosorbent removed greater quantities of $\mathrm{MB}$ than $\mathrm{CV}$.

\subsection{Effect of Initial pH}

Figure 2 shows the removal efficiency of (\%) of MB and $\mathrm{CV}$ versus initial $\mathrm{pH}$ of dye for an adsorbent dose of 2 $\mathrm{g} / \mathrm{L}$ at initial dye concentration of $50 \mathrm{mg} / \mathrm{L}$ in monocomponent systems. As it can be seen in Figure 2, the removal of the dyes is enhanced with increasing $\mathrm{pH}$. At $\mathrm{pH}$ 8, removal efficiencies were greater than $94 \%$ and $87 \%$ for $\mathrm{MB}$ and $\mathrm{CV}$ respectively. This is partly because the distribution of dye species in solution, i.e., the chemical speciation depends on $\mathrm{pH}$ of the solution. Furthermore, the net charge on the adsorbent is also dependent on solution $\mathrm{pH}$. It has been shown that the functional groups responsible for sorption properties of E. crassipes include the carboxyl and hydroxyl [35]. At $\mathrm{pH}$ higher than isoelectric point (which is around pH 2 for E. crassipes), the carboxyl and hydroxyl groups increasingly become ionized, thus resulting in more negatively charged cell walls. As a result, $\mathrm{MB}$ and $\mathrm{CV}$, being cationic dyes, have their removal increasingly augmented due to ionic attraction, levelling off around $\mathrm{pH} 10$.

\subsection{Biosorption Kinetics}

Kinetic studies are necessary to determine the equilibra

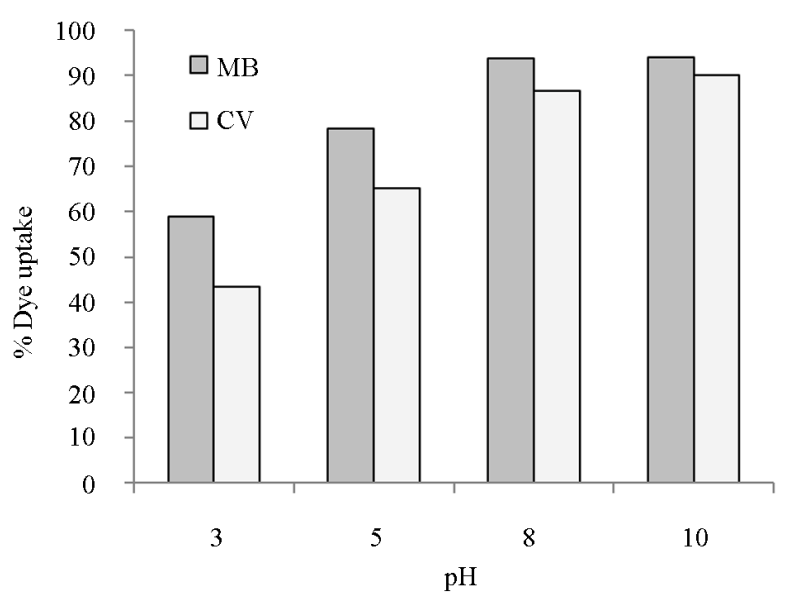

Figure 2. Effect of pH on sorption of $\mathrm{MB}$ and $\mathrm{CV}$ onto alginate- $E$. crassipes beads. 
tion time of adsorption and for the scale up of adsorption systems. The kinetics of adsorption of MB and CV onto alginate-E. crassipes was analyzed by applying the pseudo-first-order, pseudo-second-order, Elovich and intraparticle diffusion models. The pseudo-first-order model can be expressed as:

$$
\frac{d q_{t}}{d t}=k_{1}\left(q_{e}-q_{t}\right)
$$

where $q_{e}$ and $q_{t}$ are the amounts of dye sorbed at equilibrium and a given time $t$ respectively, $k_{1}$ is the first-order-rate constant. The linear form is:

$$
\ln \left(q_{e}-q_{t}\right)=\ln q_{e}-k_{1} t
$$

A plot of $\ln \left(q_{e}-q_{t}\right)$ vs. $t$ should generate a straight line with intercept of $\ln q_{e}$ and slope of $\left(-k_{1} t\right)$. Value of $q_{e}$ can be calculated and compared with that obtained via experimental.

Pseudo-second-order model can be shown as:

$$
\frac{d q_{t}}{d t}=k_{2}\left(q_{e}-q_{t}\right)^{2}
$$

where $k_{2}$ is the pseudo-second-order rate constant. The linear form is:

$$
\frac{t}{q_{t}}=\frac{1}{k_{2}\left(q_{e}\right)^{2}}+\frac{t}{q_{e}}
$$

In the limit $\frac{q_{t}}{t} \rightarrow 0$, the initial adsorption rate, $h$, is given by $h=k_{2}\left(q_{e}\right)^{2}$. Thus Equation (4) can be rearranged to obtain

$$
\frac{t}{q_{t}}=\frac{1}{h}+\frac{1}{q_{e}} t
$$

A plot of $\left(\frac{t}{q_{t}}\right)$ vs $t$ should generate a straight line with intercept of $\frac{1}{h}$, and slope of $\frac{1}{q_{e}}$.

The Elovich model is another useful model applied to the study of kinetics of biosorption and its linear form is presented by the following equation:

$$
q_{t}=\frac{1}{\beta} \ln \alpha \beta+\frac{1}{\beta} \ln t
$$

where $\alpha$ is the initial adsorption rate $\left(\mathrm{mg} \cdot \mathrm{g}^{-1} \cdot \mathrm{min}\right)$ and $\beta$ desorption constant $\left(\mathrm{g} \cdot \mathrm{mg}^{-1}\right)$. The plot of $q_{t}$ against $\ln t$ provides allows determination of $\alpha$ and $\beta$ from the slope and intercept of the plot. The other kinetic equation is the intraparticle diffusion model, given by:

$$
q_{t}=k_{i} t^{0.5}+C_{i}
$$

where $q_{t}$ is the amount of dye adsorbed $\left(\mathrm{mg} \cdot \mathrm{g}^{-1}\right)$ at time $t, k_{i}\left(\mathrm{mg} \cdot \mathrm{g}^{-1} \cdot \mathrm{min}^{-0.5}\right)$ is the rate of intraparticle diffusion controlled sorption constant, and $C_{i}$ is the intercept [36].

The kinetic parameters (pseudo-first-order kinetic constants, $k_{1}\left(\mathrm{~min}^{-1}\right)$ and $q_{e}\left(\mathrm{mg} \cdot \mathrm{g}^{-1}\right)$ as well as the coefficient of determination, $R^{2}$ ) obtained at different initial dye concentrations are given in Table 1. The results show that the equilibrium adsorption capacity for both dyes increased with initial dye concentration. Furthermore, it can be seen from the coefficient of determination values $\left(R^{2}<0.88\right)$ that the pseudo-first-order model was not suitable for describing the kinetic data. On the other hand, it can be seen from the pseudo-second-order kinetic parameters shown in Table 2 (derived from Figures 3 and 4), that the pseudo-second-order model adequately described the kinetics of the data $\left(R^{2}>\right.$ $0.98)$ for adsorption of both dyes. Interestingly, the results also showed that the $R^{2}$ values for the pseudo-first order model generally decreased as the initial dye concentration was increased, whereas the same values increased with concentration for the pseudo-second-order model. The pseudo-second order model was also tested for dye sorption from binary dye solution (Figure 5) and

Table 1. Pseudo-first-order kinetic parameters for MB and $C V$ adsorption onto alginate-fixed $E$. crassipes in single dye aqueous solutions.

\begin{tabular}{ccccc}
\hline Dye & $C_{0}\left(\mathrm{mg} \cdot \mathrm{L}^{-1}\right)$ & $k_{1}\left(\mathrm{~min}^{-1}\right)$ & $q_{e}\left(\mathrm{mg} \cdot \mathrm{g}^{-1}\right)$ & $R^{2}$ \\
\hline \multirow{4}{*}{ MB } & 50 & 13.5 & 13.2 & 0.88 \\
& 100 & 40.6 & 40.7 & 0.81 \\
& 200 & 37.7 & 87.0 & 0.77 \\
& 300 & 16.1 & 115.0 & 0.40 \\
\hline \multirow{4}{*}{$\mathrm{CV}$} & 50 & 8.71 & 10.7 & 0.80 \\
& 100 & 31.6 & 35.3 & 0.71 \\
& 200 & 22.8 & 75.2 & 0.57 \\
& 300 & 32.1 & 126.6 & 0.71 \\
\hline
\end{tabular}

Table 2. Pseudo-second-order kinetic parameters for MB and $C V$ adsorption onto alginate-fixed $E$. crassipes in single and binary dye aqueous solutions.

\begin{tabular}{ccccc}
\hline Dye & $C_{0}\left(\mathrm{mg} \cdot \mathrm{L}^{-1}\right)$ & $k_{2}\left(\mathrm{~g}^{-1} \cdot \mathrm{mg}^{-1} \cdot \mathrm{min}^{-1}\right)$ & $q_{e}\left(\mathrm{mg} \cdot \mathrm{g}^{-1}\right)$ & $R^{2}$ \\
\hline \multirow{3}{*}{ MB } & 50 & 0.00459 & 14.1 & 0.98 \\
$($ single $)$ & 100 & 0.00697 & 30.0 & 0.98 \\
& 200 & 0.00179 & 58.5 & 0.99 \\
& 300 & 0.00296 & 86.2 & 1 \\
\hline MB (binary) & 200 & 0.00925 & 29.0 & 1 \\
\hline & 50 & 0.00704 & 11.6 & 0.99 \\
CV & 100 & 0.00252 & 27.1 & 0.99 \\
(single) & 200 & 0.00298 & 54.6 & 1 \\
& 300 & 0.00159 & 86.2 & 0.99 \\
\hline $\begin{array}{c}\text { CV } \\
\text { (binary) }\end{array}$ & 200 & 0.0103 & 25.4 & 0.99 \\
\hline
\end{tabular}




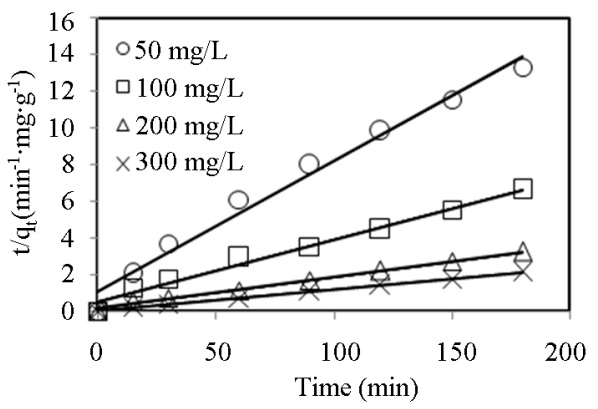

Figure 3. Pseudo-second-order kinetic plots for MB adsorption onto alginate-fixed $E$. crassipes at varying initial dye concentrations. Conditions were: $\mathbf{p H}=\mathbf{1 0}$, adsorbent mass $=0.5 \mathrm{~g}$, biomass loading $=6 \%$, volume $=150 \mathrm{~mL}$.

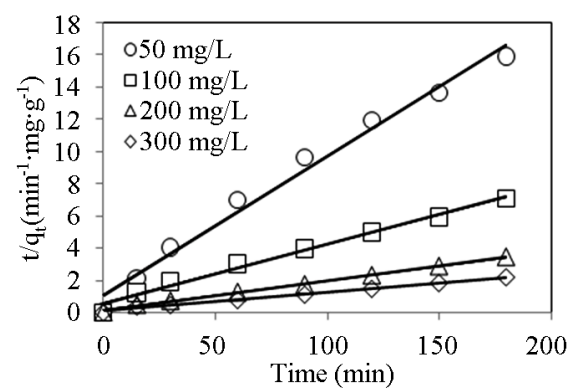

Figure 4. Pseudo-second-order kinetic plots for CV adsorption onto alginate-fixed $E$. crassipes at varying initial dye concentrations. Conditions: $\mathrm{pH}=10$, adsorbent mass $=0.5 \mathrm{~g}$, biomass loading $=6 \%$, volume $=150 \mathrm{~mL}$.

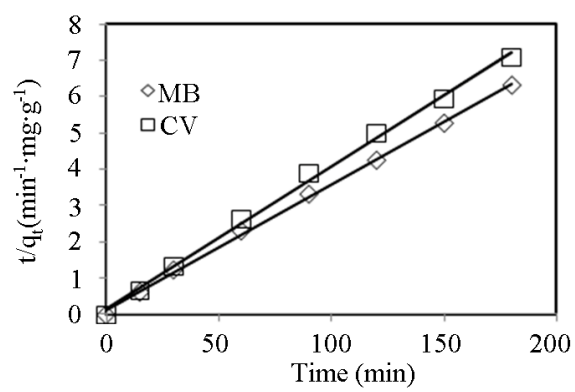

Figure 5. Pseudo-second order kinetic plots for $\mathrm{MB}$ and CV in 1:1 ratio binary dye solution system. Conditions: initial $\mathbf{p H}=10$, initial dye concentration $=200 \mathrm{mg} \cdot \mathrm{L}^{-1}$, adsorbent dosage $=0.5 \mathrm{~g}$ of $6 \%$ biomass loading, volume $=150 \mathrm{~mL}$.

the $R^{2}$ values indicate that the presence of either dye did not affect the kinetics of the adsorption process as the kinetic data were equally well described by the model. Furthermore, it can be seen that the equilibrium capacity, $q_{e}$ decreased by about one-half in the binary mixture compared to the single dye solution.

Linear plots for the Elovich model are shown in Figures $\mathbf{6}$ and 7 and the model parameters are given in Table 3. The values of $\alpha$, the initial adsorption rate, increased with increasing initial concentration for both dyes. It can be observed that for MB, $\alpha$ increased almost 200 -fold as the initial dye concentration was varied from

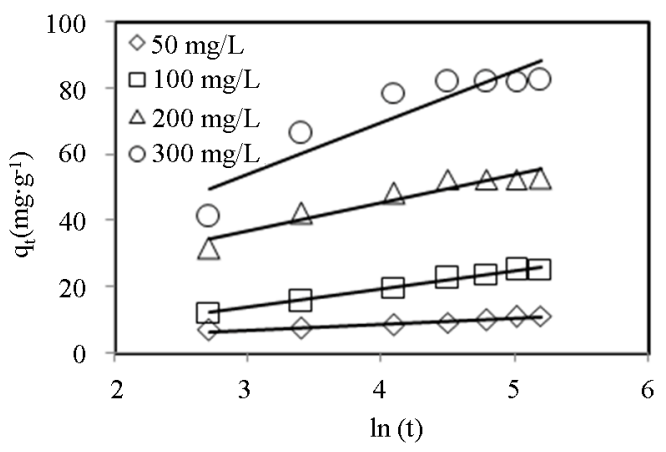

Figure 6. Elovich model plots for adsorption of $\mathrm{CV}$ onto alginate- $E$. crassipes beads at varying initial dye concentration. Conditions were: $\mathrm{pH}=10$, adsorbent $\operatorname{mass}=0.5 \mathrm{~g}$, biomass loading $=6 \%$, volume $=150 \mathrm{~mL}$.

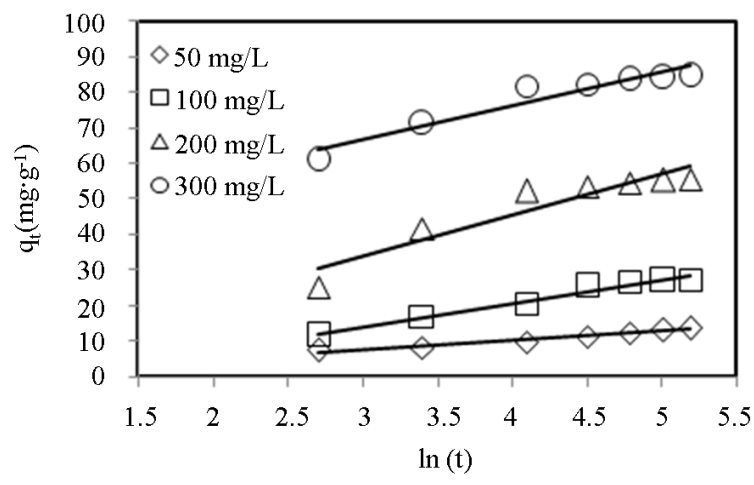

Figure 7. Elovich model plots for adsorption of MB onto alginate- $E$. crassipes beads at varying initial dye concentration. Conditions were: $\mathrm{pH}=10$, adsorbent mass $=0.5 \mathrm{~g}$, biomass loading $=6 \%$, volume $=150 \mathrm{~mL}$.

50 - $300 \mathrm{mg} \cdot \mathrm{L}^{-1}$, whereas the same parameter only increased 5-fold for CV. However, the variation of adsorption constant, $\beta$, with initial dye concentration was comparable for the two dyes. It can also be observed that the Elovich model better described the sorption data for lower dye concentration $\left(R^{2}>0.97\right)$ than for higher concentration $\left(R^{2}<0.94\right)$.

Figures 8-10 show the amount of dye adsorbed versus $t^{1 / 2}$ for the intraparticle transport of $\mathrm{CV}$ and $\mathrm{MB}$ by alginate-E. crassipes adsorbent at different initial dye concentrations, initial $\mathrm{pH}$ and biomass loading. Similar trend trends were obtained for $\mathrm{CV}$ and $\mathrm{MB}$ as the initial dye concentration was varied. It can be seen in Figures 8-10 that initial dye concentration and bead biomass loading influenced the sorption mechanism and kinetics of the dye adsorption in a comparable manner, but clearly different from the effect initial $\mathrm{pH}$. Curves in Figures 8-10 generally follow two steps at concentrations $>50 \mathrm{mg} / \mathrm{L}$, suggesting that surface adsorption and intraparticle diffusion processes are more pronounced at higher initial dye concentration. According to the first step (fast one) covering the time range between 4 and 8 
Table 3. Elovich model parameters for MB and CV adsorption onto alginate-fixed $E$. crassipes in single dye aqueous solutions.

\begin{tabular}{lcccc}
\hline Dye & $50 \mathrm{mg} \cdot \mathrm{L}^{-1}$ & $100 \mathrm{mg} \cdot \mathrm{L}^{-1}$ & $200 \mathrm{mg} \cdot \mathrm{L}^{-1}$ & $300 \mathrm{mg} \cdot \mathrm{L}^{-1}$ \\
\hline & $\beta=0.57$ & $\beta=0.18$ & $\beta=0.119$ & $\beta=0.064$ \\
$\mathrm{CV}$ & $\alpha=5.13$ & $\alpha=3.37$ & $\alpha=25.33$ & $\alpha=34.95$ \\
& $R^{2}=0.99$ & $R^{2}=0.94$ & $R^{2}=0.91$ & $R^{2}=0.84$ \\
\hline & $R^{2}=0.97$ & $R^{2}=0.97$ & $R^{2}=0.88$ & $R^{2}=0.91$ \\
MB & $\beta=0.38$ & $\beta=0.15$ & $\beta=0.106$ & $\beta=0.0862$ \\
& $\alpha=2.28$ & $\alpha=2.72$ & $\alpha=10.62$ & $\alpha=538.5$ \\
\hline
\end{tabular}

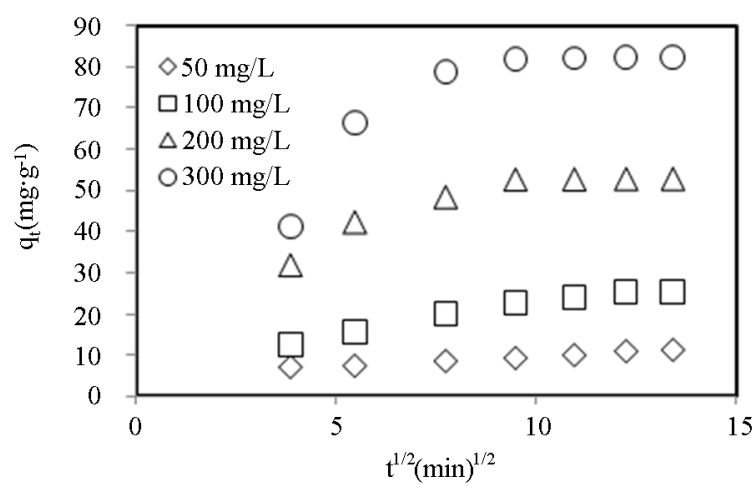

Figure 8. Intraparticle diffusion model plots for adsorption of $\mathrm{MB}$ onto alginate- $E$. crassipes at varying initial dye concentration. Conditions: $\mathrm{pH}=10$, adsorbent mass $=0.5 \mathrm{~g}$, biomass loading $=6 \%$, volume $=150 \mathrm{~mL}$.

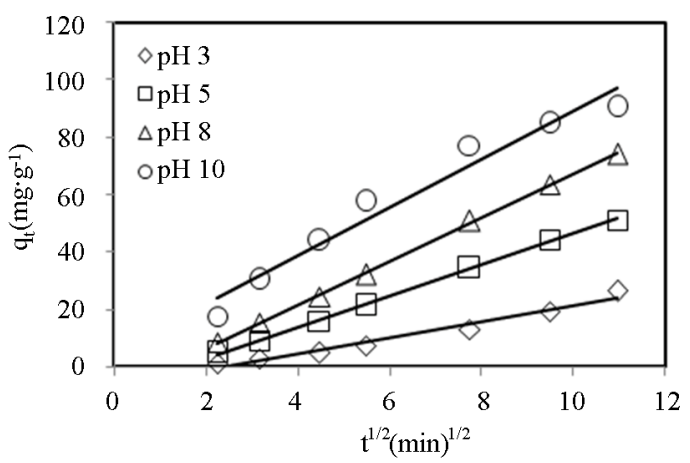

Figure 9. Intraparticle diffusion model plots for MB dye adsorption onto alginate- $E$. crassipes at varying initial $\mathrm{pH}$.

$\min$, the adsorption of dye ions onto alginate- $E$. crassipes is a surface phenomenon attributing to diffusion of the dye ions through the film solution to the external surface of the alginate-E. crassipes. The last step (the slowest one and rate determining) is the gradual adsorption limited by diffusion of solute in the liquid contained in pores of the adsorbent particles and along the pores.

\section{Conclusion}

Alginate-E. crassipes beads were used to remove basic

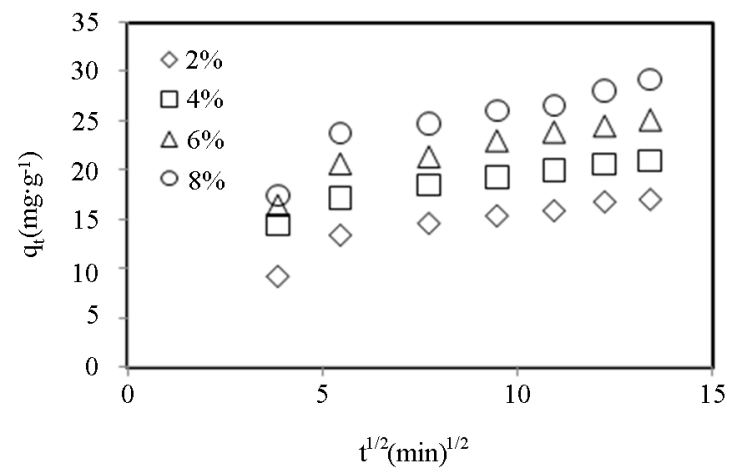

Figure 10. Intraparticle diffusion model plots for MB dye adsorption onto alginate- $E$. crassipes at varying biomass loading.

dyes Methylene Blue and Crystal Violet from aqueous solution. The results showed how solution $\mathrm{pH}$, initial dye concentration, and bead biomass loading affected dye adsorption from monocomponent and binary solution. In conclusion, it was demonstrated that $E$. crassipes fixed on alginate can potentially be used to effectively remove dyes from aqueous solution.

\section{Acknowledgements}

The International Foundation for Science, Stockholm, Sweden supported this research, through Grant Number W/4266-2 to Courtie Mahamadi.

\section{REFERENCES}

[1] N. S. Maurya, A. K. Mittal, P. Cornel and E. Rother, "Biosorption of Dyes Using Dead Macro Fungi: Effect of Dye Structure, Ionic Strength and $\mathrm{pH}$," Bioresource Technology, Vol. 97, No. 3, 2006, pp. 512-521. http://dx.doi.org/10.1016/j.biortech.2005.02.045

[2] A. Mittal, "Development of a Kinetic Model for the Biosorption of Cationic Dyes by Dead Macrofungi," Journal of Environmental Engineering, Vol. 136, No. 5, 2010, pp. 487-492.

http://dx.doi.org/10.1061/(ASCE)EE.1943-7870.0000177

[3] N. D. Lourenco, J. M. Novais and H. M. Pinheiro, "Effect of Some Operational Parameters on Textile Dye Biodegradation in a Sequential Batch Reactor," Journal of Biotechnology, Vol. 89, No. 2-3, 2001, pp. 163-174. http://dx.doi.org/10.1016/S0168-1656(01)00313-3

[4] P. P. Selvam, S. Preethi, P. Basakaralingam, N. Thinakaran, A. Sivasamy and S. Sivanesan, "Removal of Rhodamine B from Aqueous Solution by Adsorption onto Sodium Montmorillonite," Journal of Hazardous Materials, Vol. 155, No. 1-2, 2008, pp. 39-44. http://dx.doi.org/10.1016/j.jhazmat.2007.11.025

[5] A. R. Khataee, F. Vafaei and M. Jannatkhah, "Biosorption of Three Textile Dyes from Contaminated Water by Filamentous Green Algal Spirogyra sp.: Kinetic, Isotherm and Thermodynamic Studies," International Biodeterio- 
ration and Biodegradation, Vol. 83, 2013, pp. 33-40. http://dx.doi.org/10.1016/j.ibiod.2013.04.004

[6] A. R. Khataee and G. Dehghan, "Optimization of Biological Treatment of a Dye Solution by Macroalgae Cladophora sp. Using Response Surface Methodology," Journal of Taiwan Institute of Chemical Engineering, Vol. 42, No. 1, 2011, pp. 26-33. http://dx.doi.org/10.1016/i.jtice.2010.03.007

[7] A. R. Khataee, G. Dehghan, A. Ebadi, M. Zarei and M. Pourhassan, "Biological Treatment of a Dye Solution by Macroalgae Chara sp.: Effect of Operational Parameters, Intermediates Identification and Artificial Neural Network Modeling," Bioresource Technology, Vol. 101, No. 7, 2010, pp. 2252-2258.

http://dx.doi.org/10.1016/j.biortech.2009.11.079

[8] D. Kratochvil and B. Volesky, "Advances in the Biosorption of Heavy Metals," Trends in Biotechnology, Vol. 16, No. 7, 1998, pp. 291-300.

http://dx.doi.org/10.1016/S0167-7799(98)01218-9

[9] G. Crin, "Recent Developments in Polysaccharide-Based Materials Used as Adsorbents in Wastewater Treatment," Progress in Polymer Science, Vol. 30, No. 1, 2005, pp. 38-70. http://dx.doi.org/10.1016/j.progpolymsci.2004.11.002

[10] T. V. N. Padmesh, K. Vijayaraghavan, G. Sekaran and M. Velan, "Biosorption of Acid Blue 15 Using Fresh Water Macroalga Azolla filiculoides: Batch and Column Studies," Dyes and Pigments, Vol. 71, No. 2, 2006, pp. 77-82. http://dx.doi.org/10.1016/j.dyepig.2005.06.003

[11] M. Kousha, E. Daneshvar, M. S. Sohrabi, M. Jokar and A. Bhatnagar, "Adsorption of Acid Orange II Dye by Raw and Chemically Modified Brown Macroalga Stoechospermum marginatum," Chemical Engineering Journal, Vol. 192, 2012, pp. 67-76. http://dx.doi.org/10.1016/j.cej.2012.03.057

[12] M. Kousha, E. Daneshvar, M. S. Sohrabi, N. Koutahzadeh and A. R. Khataee, "Optimization of C.I. Acid Black 1 Biosorption by Cystoseira indica and Gracilaria persica Biomasses from Aqueous Solutions," Interntaionl Biodeterioration and Biodegradation, Vol. 67, 2012, pp. 56-63.http://dx.doi.org/10.1016/j.ibiod.2011.10.007

[13] V. K. Garg, M. Amita, R. Kumar and R. Gupta, "Basic Dye (Methylene Blue) Removal from Simulated Wastewater by Adsorption Using Indian Rosewood Sawdust: A Timber Industry Waste," Dyes and Pigments, Vol. 63, No. 3, 2004, pp. 243-250. http://dx.doi.org/10.1016/j.dyepig.2004.03.005

[14] C. H. Weng, Y. T. Lin and T. W. Tzeng, "Removal of Methylene Blue from Aqueous Solution by Adsorption onto Pineapple Leaf Powder," Journal of Hazardous Materials, Vol. 170, No. 1, 2009, pp. 417-424. http://dx.doi.org/10.1016/j.jhazmat.2009.04.080

[15] H. Ali and S. K. Muhammad, "Biosorption of Crystal Violet from Water on Leaf Biomass of Calotropis procera," Journal of Environmental Science and Technology, Vol. 1, No. 3, 2008, pp. 143-150. http://dx.doi.org/10.3923/jest.2008.143.150

[16] R. Ahmad, "Studies on Adsorption of Crystal Violet Dye from Aqueous Solution onto Coniferous Pinus Bark Pow- der (CPBP)," Journal of Hazardous Materials, Vol. 171, No. 1-3, 2009, pp. 767-773.

http://dx.doi.org/10.1016/j.jhazmat.2009.06.060

[17] G. O. El-Sayed, "Removal of Methylene Blue and Crystal Violet from Aqueous Solutions by Palm Kernel Fiber," Desalination, Vol. 272, No. 1-3, 2011, pp. 225-232. http://dx.doi.org/10.1016/j.desal.2011.01.025

[18] H. Chen, J. Zhao and G. Dai, "Silkworm Exuviae-A New Non-Conventional and Low-Cost Adsorbent for Removal of Methylene Blue from Aqueous Solutions," Journal of Hazardous Materials, Vol. 186, No. 2-3, 2011, pp. 1320-1327. http://dx.doi.org/10.1016/j.jhazmat.2010.12.006

[19] F. Veglio and F. Beolchini, "Removal of Metals by Biosorption: A Review," Hydrometallurgy, Vol. 44, No. 3, 1997, pp. 301-316. http://dx.doi.org/10.1016/S0304-386X(96)00059-X

[20] B. Volesky, "Detoxification of Metal Bearing Effluents: Biosorption for the Next Century," Hydrometallurgy, Vol. 59, No. 2-3, 2001, pp. 203-216. http://dx.doi.org/10.1016/S0304-386X(00)00160-2

[21] M. Z.-C. Hu and M. Reeves, "Biosorption of Uranium by Pseudomonas aeruginosa Strain CSU Immobilized in a Novel Matrix," Biotechnology Progress, Vol. 13, No. 1, 1997, pp. 60-70. http://dx.doi.org/10.1021/bp9600849

[22] L. Singh, R. P. Asalapuram, L. Ramnath and K. R. Gunaratna, "Effective Removal of $\mathrm{Cu}^{2+}$ Ions from Aqueous Medium Using Alginate as Biosorbent," Ecological Engineering, Vol. 38, No. 1, 2011, pp. 119-124. http://dx.doi.org/10.1016/j.ecoleng.2011.10.007

[23] M. Sarkar and P. Majumdar, "Application of Response Surface Methodology for Optimization of Heavy Metal Biosorption Using Surfactant Modified Chitosan Bea," Chemical Engineering Journal, Vol. 175, 2011, pp. 376387.http://dx.doi.org/10.1016/j.cej.2011.09.125

[24] S. Benamer, M. Mahlous, D. Tahtat, A. Nacer-Khodja, M. Arabi, H. Lounici and N. Mameri, "Radiation Synthesis of Chitosan Beads Grafted with Acrylic Acid for Metal Ions Sorption," Radiation Physics and Chemistry, Vol. 80, No. 12, 2011, pp. 1391-1397. http://dx.doi.org/10.1016/j.radphyschem.2011.06.013

[25] Y. Zhang, D. Kogelnig, C. Morgenbesser, A. Stojanovic, F. Jirsa, L.-I. Schultze, R. Krachler, Y. Li, K. Bernhard and B. K. Keppler, "Preparation and Characterization of Immobilized [A336][MTBA] in PVA-Alginate Gel Beads as Novel Solid-Phase Extractants for an Efficient Recovery of $\mathrm{Hg}$ (II) from Aqueous Solutions," Journal of Hazardous Materials, Vol. 196, 2011, pp. 201-209. http://dx.doi.org/10.1016/j.jhazmat.2011.09.018

[26] R. Kumar, D. Bhatia, R. Singh, S. Rani and N. R. Bishnoi, "Sorption of Heavy Metals from Electroplating Effluent Using Immobilized Biomass Trichoderma viride in a Continuous Packed-Bed Column," International Biodeterioration and Biodegradation, Vol. 65, No. 8, 2011, pp. 1133-1139. http://dx.doi.org/10.1016/j.ibiod.2011.09.003

[27] P. Xiangliang, W. Jianlong and Z. Daoyong, "Biosorption of $\mathrm{Pb}(\mathrm{II})$ by Pleurotus ostreatus Immobilized in Calcium 
Alginate Gel," Process Biochemistry, Vol. 40, No. 8, 2005, pp. 2799-2803.

http://dx.doi.org/10.1016/j.procbio.2004.12.007

[28] F. Beolchini, F. Pagnanelli, L. Toro and F. Vegliò, "Biosorption of Copper by Sphaerotilus natans Immobilised in Polysulfone Matrix: Equilibrium and Kinetic Analysis," Hydrometallurgy, Vol. 70, No. 1-3, 2003, pp. 101112.http://dx.doi.org/10.1016/S0304-386X(03)00049-5

[29] K. S. Low, C. K. Lee and K. K. Tan, "Biosorption of Basic Dyes by Water Hyacinth Roots," Bioresource Technology, Vol. 52, No. 1, 1995, pp. 79-83. http://dx.doi.org/10.1016/0960-8524(95)00007-2

[30] I. A. H. Schneider, J. Rubio, M. Misra and R. W. Smith, "Eichhornia crassipes as Biosorbent for Heavy Metal Ion," Mineral Engineering, Vol. 8, No. 9, 1995, pp. 979988.http://dx.doi.org/10.1016/0892-6875(95)00061-T

[31] M. E. Soltan and M. N. Rashed, "Laboratory Study on the Survival of Water Hyacinth under Several Conditions of Heavy Metal Concentration," Advances in Environmental Research, Vol. 7, No. 2, 2003, pp. 321-334. http://dx.doi.org/10.1016/S1093-0191(02)00002-3

[32] C. Mahamadi and T. Nharingo, "Competitive Adsorption of $\mathrm{Pb}^{2+}, \mathrm{Cd}^{2+}$, and $\mathrm{Zn}^{2+}$ Ions onto Eichhornia crassipes in Binary and Ternary System," Bioresource Technology, Vol. 101, No. 3, 2010, pp. 859-864. http://dx.doi.org/10.1016/j.biortech.2009.08.097

[33] C. Mahamadi and T. Nharingo, "Modeling Kinetic and Equilibrium Properties of Cadmium Biosorption by River Green Alga and Hyacinth Weed," Toxicological and Environmental Chemistry, Vol. 89, No. 2, 2007, pp. 297-305. http://dx.doi.org/10.1080/02772240601010063

[34] C. Mahamadi and P. Zambara, "High $\mathrm{Cu}$ Removal from Water Using Water Hyacinth Fixed on Alginate," Environmental Chemistry Letters. http://dx.doi.org/10.1007/s10311-013-0418-2

[35] M. Ibrahim, O. Kühn and T. Scheytt, "Molecular Spectroscopic Study of Water Hyacinth Dry Matter," Open Chemical Physics Journal, Vol. 2, No. 1, 2009, pp. 1-6. http://dx.doi.org/10.2174/1874412500902010001

[36] B. H. Hameed, D. K. Mahmoud and A. L. Ahmad, "Sorption Equilibrium and Kinetics of Basic Dye from Aqueous Solution Using Banana Stalk Waste," Journal of Hazardous Materials, Vol. 158, No. 2-3, 2008, pp. 499-506. http://dx.doi.org/10.1016/j.jhazmat.2008.01.098 